\title{
Derechos humanos, responsabilidad y multiculturalismo
}

\author{
LUIS VILLAR BORDA \\ Universidad Externado de Colombia
}

\begin{abstract}
RESUMEN
La responsabilidad en materia de derechos humanos es aquí analizada desde distintos ángulos. con el fin de indagar si ella compete exclusivamente a los Estados o puede cobijar otros sujetos colectivos o individuales, controversia muy actual en la que inciden no sólo razones jurídicas sino intereses políticos.

La diversidad étnica y cultural es un elemento que ha de ser tenido en cuenta en el critrerio sobre la violación de los derechos, sin que ello lleve a desconocer el carácter universal de los derechos humanos.
\end{abstract}

PALABRAS Cl.AVE

DERECHOS HUMANOS-RESPONSABILIDAD-MULTICULTURAUSMO-CIUDADANIA

ABSTRACT

The paper examines the issue of responsibility in human rights from different points of view, with the aim of inquirying whether it should be imputed exclusively to states or, likewise, to other subjects, collective or individual. In this rather topical controversy there are not only legal reasons at stake, but also political interests.

Ethnic and cultural diversity should be considered whenever a violation of rights occurs. This, however, should not override the universal character of human rights.

KEYWORDS

HUMAN RIGHTS-RESPONSIBLITY-MULTICULTURALISM-GTIEENSHIP

El tema de los derechos humanos está en el centro del debate filosófico y político contemporáneo, en lo teórico, con relación a las diversas concepciones de justicia y moralidad y en el ámbito de lo práctico, por las diferentes

Q Contrastes. Revista Interdisciplinar de Filosofia, vol. III (1998). pp. 283-305. ISSN-1136-4076

Seceión de Filosofía, Universidad de Malagł, Facultad de Filosofía y Letras

Campus de Teatinos, E-2907! Málaga (España) 
posturas de los Estados, Gobiernos y agentes públicos y privados concernidos. Lo anterior no significa que el tema no sea esencialmente jurídico, dado que el concepto mismo de derechos humanos corresponde al derecho y no puede ser confundido con los llamados «derechos morales»1.

En este sentido comparto la opinión de Jürgen Habermas sobre que «los derechos humanos tienen originariamente una naturaleza jurídica» ${ }^{2}$. Esta idea junto con la de soberanía popular determinan, según el mismo autor, «la comprensión normativa del estado democrático de derecho hasta hoy»3. Y más adelante: «El sistema del derecho no puede ser atribuído ni a una versión moral de los derechos humanos ni a una versión ética de la soberanía popular, porque la autonomía privada de los ciudadanos no puede ni anteponerse ni subordinarse a su autonomía política» 4 .

\section{DERECHOS JURIDICOS O DERECHOS MORALES}

Si bien los derechos humanos son derechos jurídicos, su fundamentación se hace desde puntos de vista morales, con apoyo en principios morales. Existen sin duda confusiones en esta materia, en algunos casos de carácter terminológico, pero que deben ser aclaradas. Nos valemos para ello de un texto muy ilustrativo de Habermas, que por esto no vacilamos en transcribir in extenso:

En la discusión filosófica esta ambivalencia [se refiere al posible doble carácter de los derechos humanos, positivo como normas constitucionales y suprapositivo como atribución a cada persona por su condición de ser humano] ha provocado resquemores. Según una de las concepciones, los derechos humanos adoptan un estatuto entre derecho moral y positivo; según otra, deben poder presentarse con el mismo contenido en la forma tanto de derechos morales como de derechos jurídicos -«como derecho preestatalmente válido, aunque no por eso ya vigente»-. Los derechos humanos «no son propiamente protegidos o negados, pero tampoco garantizados o despreciados». Estas fórmulas confusas sugieren que el Constituyente tan solo reviste las normas morales, siempre dadas, con la forma del derecho positivo. Con esta remisión a la clásica distinción entre derecho natural y legal se colocan las agujas de modo falso, según mi concepción. El concepto de derechos humanos no tiene orígen moral, sino una acuñación específica del concepto moderno de derechos subjetivos, esto es, de una terminología jurídica.

1 Para una fundamentación de los «derechos morales», véase Carlos Santiago Nino, Etica y derechos humanos. Buenos Aires: Astrea, 1989, en especial pp. 20 ss.

2 Jürgen Habermas, "La idea kantiana de la paz perpetua», Isegoría, 16 (1997), p. 81.

3 Jürgen Habermas, Faktizität und Geltung. Frankfurt am Main: Suhrkamp, 1992, p. 124.

4 Ibid., p. 134 
Los derechos humanos tienen originariamente una naturaleza jurídica. Lo que le presta la apariencia de derechos morales no es su contenido, y con mayor motivo tampoco su estructura, sino su sentido de validez, que trasciende los ordenamientos jurídicos de los Estados nacionales5.

Acredita la afirmación inicial sobre la importancia que ha tomado el debate acerca de los derechos humanos, la abrumadora bibliografía de los últimos años y en particular la presencia en la discusión de los más notables pensadores de nuestro tiempo. Esto marca a la vez el retorno de la filosofía especializada al campo, por un largo lapso abandonado, de la filosofía del derecho. Esto no significa que la filosofia del derecho se hubiere mantenido congelada desde Hegel, pues desplazada a las Facultades de Derecho, produjo, según el mismo Habermas, impresionantes realizaciones, gracias a los juristas, a quienes por ello expresa su respeto 6 .

Seguramente pensaba en Savigny y Rudolph von Jhering, con la escuela histórica y la jurisprudencia de conceptos; en John Austin y Hart, con la jurisprudencia analítica; en Llewellyn y Roscoe Pound, con el realismo norteamericano; en Georges Gurvitch y Ehrlich, con la sociologia del derecho; Karl Marx y Friedrich Engels, con una concepción materialista del derecho; en Feuerbach y von Liszt, con sus concepciones del derecho penal moderno y los derechos humanos; en Gustav Radbruch y Arthur Kaufmann, en el intento de superar el positivismo y el iusnaturalismo rígidos; en Ross, Hägerström y Olivecrona, con el realismo jurídico escandinavo; en Hermann Kantorowicz, con el movimiento de derecho libre; en Georg Jellinek, Laband y Gerber, con el positivismo del derecho público; Rommer y Welzel, en el intento de renovar el derecho natural; en Léon Duguit, con su escuela solidarista, y no en último término en Hans Kelsen, con su Teoría Pura del Derecho y la escuela de Viena, que él encabezó y a la que pertenecieron Verdross, Merkl, Pitamic, Josef L. Kunz, Felix Kaufmann, Legaz y Lacambra, Recasens Siches, Garcia Maynez, Fritz Sander y Charles Eisenmann, entre otros.

La enumeración no es naturalmente exhaustiva ni se mencionan los más recientes movimientos y tendencias, que en especial a partir de la década de los setenta están enriqueciendo enormemente la Filosofía del Derecho y la Teoría Jurídica. Basta referir algunos de los acontecimientos capitales en este periodo: la publicación en 1971 de la Teoría de la justicia de John Rawls, y Facticidad y validez de Jürgen Habermas, en 1992, que testimonian la aseveración acerca del regreso de la filosofía especializada a la filosofía del Derecho ${ }^{7}$.

5 Jürgen Habermas, «La idea kantiana de la paz perpetua», p. 80.

6 Faktizität und Geltung, p. 11.

7 Ralf Dreier, «Rechtsphilosophie und Diskurstheorie», Zeitschrift für Philosophische Forschung, 48 (1994), pp. 90-103. 
DERECHOS HUMANOS PARA RAWLS

En su opúsculo sobre el Derecho de los Pueblos (o Derecho de Gentes) 8 busca Rawls extender la teoría de la justicia, presentada por el autor como «justicia como equidad", al campo de las relaciones internacionales, en el proyecto en enmarcar ese derecho en una idea liberal de la justicia. El núcleo de esa construcción lo conforman los derechos humanos.

Rawls señala que «esos derechos no dependen de ninguna doctrina moral comprehensiva o concepción filosófica de la naturaleza humana según la cual, por ejemplo, todos los seres humanos son personas morales y tienen igual dignidad $\mathrm{u}$ ostentan ciertos poderes morales $\mathrm{e}$ intelectuales particulares que les invisten de esos derechos»9. Para él el enfoque es distinto. «Los derechos humanos fundamentales expresan un patrón mínimo de instituciones políticas bien ordenadas para todos los pueblos que pertenecen, como miembros de buena fe, a una justa sociedad política de los pueblos»10.

Previamente habría que decir que Rawls busca superar, en lo que respecta a los derechos humanos, la polémica entre «universalistas» y «multiculturalistas» y «comunitaristas», al establecer una división de las sociedades entre sociedades liberales (bien ordenadas) y sociedades jerárquicas, que son susceptibles de estar bien ordenadas.

Para ese efecto, es decir, con el fin de declarar una sociedad jerárquica como bien ordenada y en consecuencia con aceptación para quedar incorporada a la extensión de la idea liberal de justicia del derecho de los pueblos (de gentes), se requiere una serie de requisitos, a saber: a) que la sociedad sea pacífica y persiga sus fines a través de la diplomacia, el comercio y demás medios pacíficos; b) que el sistema jurídico de esa sociedad imponga deberes y obligaciones morales a todas las personas residentes en su territorio, se guie por una idea de justicia que comporte el bien común y que los jueces y administradores jurídicos confien de buena fe en que el derecho está orientado por esa concepción de justicia; c) formas apropiadas de ser escuchados, según los valores religiosos o filosóficos de esa sociedad; $y$ d) posibilidad de disentimiento.

Se trata, pues, de asegurar un cierto número de «derechos mínimos», que podrían considerarse como suficientes para que tal sociedad se estime que respeta los derechos fundamentales. Se excluye la violación de los derechos humanos y se prevee una «razonable jerarquía consultiva» que los proteja. Para

8 John Rawls, El derecho de los pueblos. Estudio preliminar de Oscar Mejía, tr. C. Montilla. Bogotá: Tercer Mundo, 1996. El mismo trabajo aparece traducido como «Derecho de gentes» en la revista española Isegoría, 16 (1997).

9 John Rawls, El derecho de los pueblos, p. 25.

10 lbid. 
Rawls los derechos humanos conforman una categoría especial de derechos, referidos de manera central a un derecho razonable de los pueblos (de gentes). Los derechos humanos fijan límite a la soberanía de los Estados, dentro de la nueva concepción surgida después de la catástrofe de la segunda guerra mundial. Esto induce a que sean considerados como derechos aplicables a todos los pueblos, en la medida en que conformen naciones que hagan parte de buena fe de la comunidad internacional y sin que eso implique la posibilidad de imponer sistemas políticos a aquellos que se apartan de los órdenes liberales ordenados. En síntesis, los derechos humanos tienen para Rawls las siguientes funciones:

1. Son condición necesaria de la legitimidad del régimen y de la decencia de su orden jurídico.

2. Cuando operan en debida forma, resultan suficientes para excluír la justificada intervención de otros pueblos mediante sanciones económicas o, en casos graves, la fuerza militar; $y$

3. Fijan un límite al pluralismo entre los pueblos"I.

El problema que se plantea, y al cual vuelve Rawls al final de su escrito, es el de los límites de la tolerancia con las por él llamadas sociedades jerárquicas. Los gobiernos dictatoriales y tiránicos y los regímenes expansionistas, es decir propugnadores de la guerra de conquista, quedan excluídos. Pero al mismo tiempo, no puede imponerse un orden liberal a todas las sociedades, sin tener además en cuenta su estado de desarrollo económico y cultural o simplemente las diferencias de ideas de la justicia y de tradiciones y hábitos culturales. Parte de la tolerancia es que una sociedad liberal respete a otro tipo de sociedades. No se trata de imponer una particular concepción del bien, sino de llegar a un acuerdo sobre una concepción política pública de la justicia, que no esté fundado en una determinada idea de la moral, y puede ser aceptado tanto por las sociedades liberales como por las sociedades jerárquicas, es decir por el conjunto de la comunidad internacional de naciones en condiciones y con capacidad para convivir pacíficamente.

La condición sine qua non de ese acuerdo es el respeto a los derechos humanos, entendidos como «derechos mínimos» aceptados y reconocidos en cualquier sociedad «decente», es decir, digna de ser miembro de la comunidad de naciones, así su régimen político no se conforme al paradigma del ordenamiento liberal. Como lo expresa Oscar Mejía: «El paradigma consensual del derecho, como toda concepción pública de justicia y como todo orden institucional, sea cual sea la estructura básica que los sustente y la naturaleza de la sociedad que les haya dado su orígen, tienen en la garantía y respeto de

11 Ibid., p. 28 , 
los derechos humanos la condición final y definitiva de su razón de ser, así como de su legitimidad y valídez moral, social y jurídica» 12 .

El esfuerzo de Rawls por ampliar su teoría a la esfera internacional no dejará de ser observado, en algunos aspectos, como concesión a las redobladas críticas de los comunitaristas, antiuniversalistas y multiculturalistas. Es evidente, como lo observa Brian Barry, que a menudo se exageran las diferencias culturales hasta el punto de considerar inconmesurables unas sociedades con otras. Es el legado de los nacionalismos románticos, además de los fundamentalismos religiosos o filosóficos ${ }^{13}$. Barry sigue la misma línea de Rawls en cuanto a formular una concepción de la justicia no sujeta a determinadas concepciones del bien o de la moral, que él denomina justicia como imparcialidad, la cual no requiere de la idea rawlsiana de "posición original», por cierto una de las más criticadas de su teoría, y que Barry, a pesar de considerarla en extremo inteligente, juzga que falla al final. Podría, pues, hablarse de una corrección a la Teoría de Rawls, pero no de su rectificación fundamental ${ }^{14}$.

José Rubio-Carracedo estima que la crítica comunitaria y sus formulaciones alternativas, «han ido frecuentemente demasiado lejos y no solo en su ala más conservadora» 15 . Considera certeras sus críticas al formalismo, «la abstracción y la estrechez del concepto de justicia» (liberal) y señala que ellas han originado rectificaciones, de la misma manera que «ha sido acertada su denuncia del sujeto liberal «sin atributos», esto es, sin ligaduras comunitarias y familiares, así como su reivindicación de la comunidad frente a la sociedad homogénea liberal»16.

Pero al mismo tiempo desconceptúa otras críticas por demasiado globales, unilaterales o equivocadas. El concluye que «existe un único paradigma moral vehiculado por el principio justicia-solidaridad-autonomía, en el sentido de que la justicia (derechos humanos) marca el mínimo moral prioritario y universalizable, a la vez que garantiza que la solidaridad sea auténtica (esto es, no viole los derechos); la solidaridad, por su parte, se revela como el sentido último de la justicia, además de marcar la via del perfeccionamiento moral; por último la autonomía marca la madurez moral tanto en la justificación como en la aplicación ética en su triple nivel: autonomía de la razón práctica, autonomía del grupo deliberativo y autonomía irrenunciable del sujeto personal en su elección final. No es posible una moralidad auténtica sin el cumplimiento de

12 Oscar Mejía, «El paradigma consensual del derecho en la teoría de la justicia de John Rawls», Estudio preliminar a John Rawls, El derecho de los pueblos, p. 72.

13 Brian Barry, La justicia como imparcialidad. Barcelona: Paidós, 1997, pp. 25 ss.

14 Ibid., p. 31.

I5 José Rubio-Carracedo, Educación moral, postmodernidad y democracia. Madrid: Trotta, 1996, p. 113.

$16 \mathrm{Ibid}$. 
este único principio poliédrico: la justicia no es completa sin la solidaridad y la autonomía; la solidaridad no es completa sin la justicia y la autonomía; y la autonomía no es auténtica sin la justicia-solidaridad»17. La posición de RubioCarracedo es, pues, de síntesis y supera la parcialidades de «universalistas» y "comunitaristas", en una aspiración que abrigan igualmente Kymlicka y Brian Barry, así sea por otras razones, como en este mismo texto lo enunciamos.

\section{DERECHOS HUMANOS Y DERECHOS DE LAS MINORIAS}

La irrupción violenta de conflictos raciales, religiosos, nacionales, sociales, después de lo que se anunciaba como una era de predominio universal de las ideas liberales e incluso de «fin de la historia»18, es una nueva manifestación de la astucia con que la propia historia suele vengarse de sus acuciosos profetas.

La realidad, a pocos años del derrumbe del socialismo burocrático, la disolución de la Unión Soviética, y el fin de la «guerra fría», es bien distinta. A pesar de la proclamación de las Cartas universales y regionales de derechos y su inclusión como derechos fundamentales en casi todas las Constituciones del mundo, y el indudable avance de los movimientos en favor de los derechos humanos, así como el establecimiento de organismos encargados de su vigilancia, el balance actual es verdaderamente desconsolador.

De un lado aparecen con características dramáticas los genocidios y masacres en Argelia, Colombia, Bosnia, Ruanda, Congo, Burundi, las repúblicas asiáticas ex-soviéticas, para citar apenas algunos países, pero del otro, sin que esto haga habitualmente «noticia», la discriminación de pueblos y naciones enteras, la agonía de etnias atropelladas por la «civilización» y la situación de las minorías dentro de los propios límites territoriales de sus países. Además, se trata de olvidar con frecuencia que el estado de miseria y desamparo de decenas de millones de seres humanos, agravado por las nuevas políticas de globalización, privatizaciones a ultranza, marginación de los poderes públicos de la obligación de atender a los más débiles y necesitados, desmonte de los sistemas de seguridad social, entre otras consecuencias del ultra-liberalismo económico, entraña un agravio a los derechos humanos y a sus fundamentos esenciales, la dignidad e igualdad de los seres humanos.

Will Kymlicka nos informa en su obra Ciudadanía multicultural ${ }^{19}$, que actualmente existen más de 600 grupos de lenguas vivas en los 184 Estados independientes del mundo y más de 5.000 grupos étnicos, lo cual da la idea de las dimensiones del tema. «Esta diversidad», escribe Kymlicka, «plantea una

17 Ibid., p. 133.

18 Francis Fukujama, El fin de la historia y el último hombre. Barcelona: Planeta, 1992, p. 446.

19 Will Kymlicka, Ciudadania multicultural. Barcelona: Paidós, 1996. 
serie de cuestiones importantes y potencialmente divisivas. Así, minorías y mayorías se enfrentan cada vez más respecto de temas como los derechos lingüísticos, la autonomía regional, la representación política, el curriculum educativo, las reivindicaciones territoriales, la política de inmigración y naturalización, e incluso acerca de símbolos nacionales, como la elección del himno $y$ las festividades oficiales» 20 .

En especial en el llamado Tercer Mundo los conflictos de minorías amenazan las instituciones democráticas, sin que ello signifique que en los países desarrollados no existan los mismos peligros. Los liberales creyeron en principio que era suficiente la atribución de derechos iguales para todos, sin proteger o privilegiar determinados grupos, para realizar la idea de igualdad, una igualdad que obviamente lo era solo «ante la ley», es decir una ficción.

La realidad ha demostrado que no bastaba con los derechos tradicionales, sino que éstos debían complementarse con derechos de las minorias. Kymlicka observa cómo es posible, $y$ de hecho ha ocurrido con grupos como los nazis o los partidarios del apartheid, que existan minorias que abusen de derechos preferenciales. También podría decirse esto dentro de los propios grupos, cuando tales derechos sirven para que una élite domine o explote a los demás miembros del grupo protegido. Por eso es tan importante establecer las condiciones para que los derechos de las minorías puedan conciliarse con los derechos humanos, a fin de que puedan coexistir sobre bases de «libertad individual, democracia y justicia social»21.

Kymlicka estima que la polémica entre individualistas y colectivistas, o sea, sobre si «las comunidades pueden tener derechos e intereses independientemente de sus miembros individuales ${ }^{22}$, conduce a resultados desastrosos y es inútil» a la hora de evaluar la mayoría de los derechos diferenciados en función del grupo en las democracias occidentales»23. El punto es que a miembros de grupos diferentes se les otorguen derechos diferentes, lo cual es casi siempre ajeno a que la comunidad tenga o no predominio sobre el individuo. Esto no quiere decir que no existan «derechos colectivos», sino simplemente que no deben confundirse con la ciudadanía diferenciada.

La tentativa de Kymlicka es la de demostrar que los derechos diferenciados «en función de grupo para las minorías son coherentes con los principios básicos de libertad individual y justicia social, así como que las habituales objeciones liberales que se basan en dichos principios son poco convincentes» 24 . Se trata de mirar la diversidad étnica y cultural no como un desastre y un inevitable foco
20 Ibid., p. 13.
21 Ibid., p. 19.
22 Ibid., p. 76.
23 Ibid.
24 Ibid., p. 239. 
de conflictos, sino de orientar políticas multiculturales, incluso en búsqueda de una ciudadanía multicultural, que a base de tolerancia y de ubicar aquellos puntos que unen a los hombres con respecto de sus diversidades, se puedan encauzar hacia la justicia. Esos derechos tendrían dos límites: primero, que no condujesen al dominio de un grupo sobre otros; segundo, que no permitan la opresión del grupo sobre sus miembros. De qué manera incide todo lo que anteriormente se ha expuesto en la responsabilidad por la violación de los derechos humanos, es algo de lo cual nos ocuparemos adelante.

\section{DERECHOS ÉTNICOS Y EXPLOTACIÓN DE RECURSOS EN COLOMBIA}

La última Constitución de Colombia fue generosa en la inclusión de derechos a favor de las comunidades indígenas, $\mathrm{y}$ los diversos grupos étnicos y culturales, comenzando por sus artículos $7^{\circ}$ y $8^{\circ}$, conforme a los cuales «El Estado reconoce y protege la diversidad étnica y cultural de la Nación», y «Es obligación del Estado y de las personas proteger las riquezas culturales y naturales de la Nación", respectivamente 25 . Varias otras disposiciones corroboran o desarrollan esos principios. En particular, para el caso que nos interesa, el artículo 330 , que institucionaliza los territorios indígenas, y en el cual se establece, entre otras disposiciones, que «la explotación de los recursos naturales en los territorios indígenas se hará sin desmedro de la integridad cultural, social y económica de las comunidades indígenas. En las decisiones que se adopten respecto de dicha explotación, el gobierno propiciará la participación de los representantes de las respectivas comunidades».

La abundancia de normas «protectoras» no significa que en la realidad haya cambiado fundamentalmente la situación de esas comunidades, que habitan, tanto la población indígena como la negra, las regiones menos desarrolladas del país. .

Una de esas etnias, la comunidad U'wa, que habita una extensa zona en la parte nororiental de Colombia, quedó cobijada por la licencia otorgada por el Gobierno a la Compañía Occidental de Colombia, Inc. para iniciar explotaciones sísmicas a fin de comprobar la existencia de yacimientos petrolíferos y adelantar el proyecto de explotación de hidrocarburos.

El pueblo U'wa, cuyos valores culturales y religiosos profundamente arraigados en el grupo son opuestos a lo que consideran la «destrucción de territorio sagrado», que pone en peligro la supervivencia misma de la comunidad, llegó a amenazar con un suicidio colectivo en el caso de que se insista en

25 En realidad se trata de la incorporación de normas correspondientes a obligaciones adquiridas por Colombia en pactos internacionales, que consagran determinados derechos especiales de protección de grupos étnicos, entre ellos el Pacto Internacional de Derechos Civiles y Políticos (Nueva York, 16 de diciembre de 1966) o el convenio 169 de la OrT. 
adelantar el proyecto, aún en el caso de cumplirse en debida forma la consulta a que tienen derecho. No habiendo sido tenidos en cuenta sus razonamientos por el Ministerio de Medio Ambiente, órgano estatal que otorgó la licencia, el grupo, por medio del Defensor del Pueblo, acudió a la Corte Constitucional en ejercicio de la acción extraordinaria de tutela, para la revisión de la intentada ante la jurisdicción ordinaria. En su demanda se dijo, entre otras cosas, que «respecto a la explotación de recursos naturales no renovables en territorios indígenas, está condicionada al mantenimiento de la integridad cultural, social y económica de las comunidades indígenas y a la participación de sus representantes en las decisiones que se adopten respecto de dicha explotación".

Estamos frente a un típico conflicto de intereses en el que juega papel definitivo la ponderación que haga el intérprete y juzgador. La Corte Constitucional26, estimó que el artículo 330 ya citado da solución a dicho conflicto, al estatuir que la explotación de recursos naturales en los territorios indígenas «se hará sin desmedro de la integridad cultural, social y económica de las comunidades indígenas». A esto se agrega el derecho fundamental de participación de la comunidad indígena para la toma de decisiones, reforzado además por el Convenio 169 de la OIT sobre derechos de las minorías étnicas, que fue aprobado y ratificado por Colombia y hace parte por ello de su ordenamiento jurídico constitucional. Sin entrar a las numerosas e ilustradas consideraciones que hace la Corte, es suficiente decir que ella considera que se busca evitar la consumación de un "perjuicio irremediable», como sería el causado con «la violación de los aludidos derechos fundamentales», que de persistir, «puede llegar a un punto de no retorno, como sería la destrucción o aniquilación del grupo humano U'wa».

La tutela fue aceptada, esto es, se dispuso la consulta de la comunidad, pero quedó pendiente la resolución del asunto de fondo, esto es el de si hay o no menoscabo de la integridad étnica y cultural del pueblo U'wa. Al mismo tiempo se difiere a la jurisdicción de lo Contencioso Administrativo la decisión final en relación con la resolución que otorgó la licencia. En estas condiciones, el Consejo declaró la legalidad de la licencia, el problema siguió vivo y obligó al pueblo U'wa a acudir a la Comisión Interamericana de Derechos Humanos (CIDH), la cual asumió el caso y recomendó, con base en un Informe a la Universidad de Harvard y de la OEA, no iniciar ninguna labor de exploración en el territorio U'wa27.

26 Corte Constitucional de Colombia, Sentencia Número 039/97.

27 De conformidad con el Sistema Interamericano, la Convención de 1969 sobre Derechos Humanos estableció dos órganos para garantizar su cumplimiento: La Comisión Interamericana de Derechos Humanos y la Corte Interamericana de Derechos Humanos, que se suponen «autónomas», pero en realidad sus integrantes son escogidos por los propios Estados miembros de la Organización (OEA). La primera, por ejemplo, recibe quejas, adelanta averiguaciones, rinde informes e, incluso, puede proponer medidas. 
Interesa destacar con este caso es la manera como el concepto de «derechos humanos» y áun más el de «derechos fundamentales» es diferentemente interpretado de acuerdo con la diversidad de culturas, lo cual evidentemente afecta también la noción acerca de la responsabilidad por la violación de tales derechos.

$$
\text { DERECHOS ÉTNICOS Y PUNICIÓN }
$$

Una situación más compleja y un caso más difícil que el relacionado con el derecho fundamental de los U'wa a ser consultados toda vez que esté amenazada su personalidad cultural, es el que tiene que ver con la aplicación de las normas penales generales del país o las de los respectivos grupos étnicos, en el caso de la realización de hechos considerados criminales por las dos culturas, la nacional y la de comunidad indígena. Por ejemplo, delitos de homicidio, lesiones o hurto y robo. Aquí no se trata solo de la competencia para el conocimiento de tales ilícitos $\mathrm{u}$ otros hechos igualmente penados, cuando son cometidos por miembros de una comunidad indígena, sino también del tipo de penas que deban aplicarse.

No pocas controversias desató la decisión de la Corte Constitucional28 negando la acción de tutela (amparo) de un indígena de la comunidad paez, quien consideró violados sus derechos a un debido proceso y a la vida y a la igualdad, en razón de la sanción que le fue impuesta por su propia Comunidad, por la comisión de un delito de homicidio. Dejando de lado el aspecto relativo a la competencia, deseamos llamar la atención sobre el del tipo de pena impuesto (sesenta fuetazos), el cual fue considerado por la parte actora como idéntico con la tortura, que la propia Corte había estimado el límite a la autonomía de las comunidades indígenas.

Luego de juiciosas disquisiciones acerca de las tensiones originadas en la diversidad étnica y la necesidad de plantear «un diálogo intercultural que sea capaz de trazar unos stándares mínimos de tolerancia que cubran los diferentes sistemas de valores», se reafirma el criterio de privilegiar la «maximización de la autonomía de las comunidades indígenas», como única forma de lograr su superviviencia cultural. La limitación se radica en lo que verdaderamente resulta intolerable por atentar contra los bienes más preciosos del hombre (derecho a la vida, prohibición de la esclavitud, de la tortura, legalidad en el procedimiento, en los delitos y las penas, entendido el juzgamiento dentro de los procedimientos y normas de la comunidad indígena).

$\mathrm{Al}$ referirse a la cuestión del fuete, la sentencia dice que «muestra claramente una tensión entre dos tipos de pensamiento: el de la sociedad mayoritaria y el de la comunidad indígena paez. En el primero, se castiga porque se cometió un delito, en el segundo se castiga para restablecer el orden de la naturaleza y para 
disuadir a la comunidad de cometer faltas en el futuro. El primero rechaza las penas corporales por atentar contra la dignidad del hombre, el segundo las considera como un elemento purificador, necesario para que el mismo sujeto, a quien se imputa la falta, se sienta liberado». ¿Frente a esta disparidad de visiones, es dable privilegiar la visión mayoritaria? La Corte ya ha respondido a esta cuestión: No, porque en una sociedad que se dice pluralista ninguna visión del mundo debe primar y menos tratar de imponerse; y el caso específico de los grupos aborígenes, de acuerdo con los preceptos constitucionales, se exigen el máximo respeto». Obviamente con las restricciones ya mencionadas.

Queda pendiente la cuestión del fuete. Luego de definir la tortura y distinguirla de otras penas corporales, recurriendo incluso a la Corte Europea de Derechos Humanos y mencionando antecedentes y casos, se explica que el «fuete consiste en la «flagelación con perrero de arriar ganado», que en este caso se ejecuta en la parte inferior de la pierna [...] aunque indudablemente produce aflicción, su finalidad no es causar un sufrimiento excesivo, sino representar al elemento que ha de purificar al individuo, el rayo. Es, pues, una figura simbólica o, en otras palabras, un ritual que utiliza la comunidad para sancionar al individuo y devolver la armonía [...]. En este caso, y al márgen de su significado simbólico, la Corte estima que el sufrimiento que esta pena pueda causar al actor, no reviste los niveles de gravedad requeridos para que pueda considerarse como tortura, pues el daño corporal que produce es mínimo» 29 . Tampoco es «humillante», por su carácter tradicional, además es un medio para que el individuo recobre su puesto en la comunidad.

Esta claro que se trata de la ponderación entre derechos excluyentes, en donde debe ceder aquel que se considera proporcionalmente más valioso para el caso concreto controvertido y de ninguna manera como una generalización universal. Desconocer el derecho de la comunidad indígena a aplicar sus propias normas, dentro de las restricciones ya conocidas, sería tanto como propiciar su aniquilamiento. Es probable, por supuesto, que al contacto con otras culturas o «diálogo intercultural» se vayan modificando los criterios de sanción de las propias Comunidades indígenas. Pero esto no puede ser obra de la represión o la imposición de culturas más poderosas o mayoritarias, frente a las cuales han sobrevivido a pesar de una larga cadena de persecusiones, marginamientos y abusos.

RESPONSABILIDAD POR LA VIOLACIÓN DE LOS DERECHOS HUMANOS

El tema de la responsabilidad por la violación de los derechos humanos, con ser de tanta trascendencia, no ha sido punto central en las discusiones, como ya

29 Sentencia Número 523/97. 
lo decíamos en extremo abundantes, sobre la materia. Sin embargo, cada día más despierta el interés en virtud de las consecuencias jurídicas, políticas y prácticas que conlleva.

En trabajo sobre el tema ${ }^{30}$ planteaba el siguiente interrogante: «Es exclusivamente el Estado, como lo sostiene una doctrina ortodoxa, responsable tanto de la preservación como del desconocimiento e infracción de estos derechos, o tal responsabilidad puede extenderse a otros actores, como entidades trans-nacionales, grupos subversivos, asociaciones supra-estatales o, incluso, organizaciones criminales, según pretenden otras corrientes de la filosofía jurídica y el derecho internacional ?» Esto es lo que se tratará de responder, con referencia además a la última y vigente Constitución de Colombia (1991).

Ya atrás nos referíamos a las discrepancias que existen en la interpretación, sea a la luz de las diversas tendencias liberales, del comunitarismo y el multiculturalismo, a lo cual habría de agregarse las de aquellos que niegan la propia existencia de derechos humanos, algo que introduce una fuerte carga ideológica al debate. Así lo señalaba Ottfried Höffe al decir que «existen principios jurídicos que como su nombre lo indica tienden a la universalidad, se trata de los derechos humanos. Estos vieron la luz en Occidente y sus formas tradicionales de legitimación se sirven de elementos de carácter occidental. Los derechos humanos son por esta razón un ejemplo de lo que en otro momento se denominó ideología, o sea, una institución de derechos que se ha definido como universal cuando en realidad su validez no es sino parcial»31. Sin embargo, ya vimos también cómo el esfuerzo hoy va dirigido a conciliar los derechos humanos con los de las minorías, a fin de superar esa contradicción entre universalismo y particularidades culturales, en lugar de acentuarla. Todas las civilizaciones tienen principios básicos que, sin desconocer sus propias tradiciones, pueden fundamentar los derechos humanos.

Cuando los europeos reclaman la invención de los derechos humanos, cuyos antecedentes y pre-historia son muy antigüos ${ }^{32}$, no podrían olvidar que la idea central en que se fundan, la de humanidad y dignidad moral del hombre vienen de culturas clásicas aún más arcaicas, con sus concepciones éticas, que por cierto ocupan cada día más la atención de los estudiosos ${ }^{33}$. La vinculación de estas tradiciones con las ideas modernas de derechos humanos y democracia no puede descartarse.

30 Luis Villar Borda, ponencia en el Congreso Mundial de Filosofía del Derecho, Buenos Aires 1997.

31 Ottfried Höffe, Los principios universales del derecho y la relatividad cultural. Bogotá: Diálogo Científico.

32 Carlos Santiago Nino, Etica y derechos humanos. Buenos Aires: Astrea, 1989; Gregorio Peces-Barba, Derecho positivo de los derechos humanos. Madrid: Debate, 1987.

33 Heiner Roetz, Die Chinesische Ethik der Achsenzeit. Frankfurt am Main: Suhrkamp. 1992. 
El gran progreso occidental fue ciertamente el de elaborar catálogos de derechos y darles forma escrita, desde la Declaración de Derechos del Hombre y del Ciudadano de la Francia revolucionaria de 1789, la Declaración de Derechos del Buen Pueblo de Virginia de 1776, la Declaración de Independencia de los Estados Unidos de 1796, hasta la Declaración universal de derechos humanos de 1948 , para no mencionar sino las de mayor eco mundial. En obra dirigida por Gregorio Peces-Barba Martínez ${ }^{34}$ se hace un inventario bastante amplio de documentos anteriores y posteriores, que ilustran la venerable tradición en esta materia.

La vocación de universalidad de los derechos humanos no puede traducirse en uniformidad ni menos en instrumento político para imponer determinadas formas de vida. Pero es incuestionable que los Estados tienen la obligación de comportarse, como miembros de la comunidad internacional, con responsabilidad frente a sus nacionales y extranjeros residentes en su territorio, conforme a preceptos estatuídos en las convenciones por ellos mismos aprobadas o aceptadas. Como lo observa Antonio Cassese ${ }^{35}$, «cada Estado ha de rendir cuentas a los demás países y a ciertos organismos internacionales, sobre el trato que se da, en su interior, a los extranjeros, y no sólo a ellos, sino también a sus propios ciudadanos. Gráficamente, cada Estado ha de convertirse en una casa de cristal».

\section{DERECHOS HUMANOS Y DERECHOS FUNDAMENTALES}

Ante el sinnúmero de problemas que se asoman por la versatilidad del concepto de derechos humanos y la diversidad de definiciones que se han ensayado en torno a él, ya sea como principio ético-filosófico o norma jurídica del derecho interncinal, la teoría moderna, principalmente de orígen alemán, ha optado por el término de «derechos fundamentales» cuando se trata de derechos humanos positivados, es decir consagrados como derecho positivo por la Constitución Política. La mayor parte de las nuevas Constituciones han seguido esa tendencia, y entre ellas la de Colombia 1991.

Robert Alexy diferencia cuatro posiciones básicas, en las discusiones acerca de los derechos humanos, la «aristotélica», la «hobbesiana», la «kantiana» y la «nietzscheana» 36 . Al defender una concepción kantiana, le atribuye, como a todas las variantes de esta tendencia, los principios de autonomía y universalidad. «En la autonomía pública están ligados derechos humanos y democracia. La protección y factibilidad de ambas formas de autonomía es la primera tarea de los derechos humanos en la concepción kantiana. Un desarrollo pleno tanto de la autonomía privada como de la pública sólo es posible en un estado constitucio-

34 Gregorio Peces-Barba, op, cit.

35 Antonio Cassese, Los derechos humanos en el mundo contemporáneo. Barcelona: Ariel, 1993.

36 Robert Alexy, Teoría del discurso y derechos humanos, tr. Luis Villar Borda. Bogotá: Universidad Externado de Colombia, 1995. 
nal democrático, en el cual los derechos humanos han tomado la forma de derechos fundamentales. Cuando en adelante se hable a menudo de «derechos fundamentales» en lugar de «derechos humanos», se conceptúa en esta conexión» 37 .

$\mathrm{La}$ anterior precisión metodológica arroja claridad sobre la situación interna de los Estados, pues difiere la definición de los «derechos humanos» a la Constitución, convirtiéndolos en derechos fundamentales, esto es, derechos humanos transformados en normas positivas. Ya veremos cómo afecta esto la responsabilidad de terceros. Pero no resuelve el problema de la responsabilidad internacional por la violación de los derechos humanos.

Podría entenderse que estos son, como los denominan algunos autores, «derechos morales»38. Manuel Atienza recoge la posición de Nino sobre esta materia, al afirmar que «Los derechos humanos son aquellos derechos subjetivos cuya titularidad se atribuye a las personas (es una cuestión discutida si los únicos titulares de derechos humanos son los individuos, no los grupos) por simple hecho de serlo. Esos derechos con minúscula, puesto que se trata de derechos subjetivos) son simplemente derechos morales cuando no están reconocidos por el derecho positivo (ahora con mayúscula, porque nos estamos refiriendo al Derecho objetivo, el derecho como conjunto de normas). Cuando están incorporados al derecho positivo, es decir, forman parte de la Constitución, se les suele llamar derechos fundamentales» 39 .

El profesor Antonio E. Pérez Luño, luego de un detenido análisis de los diferentes tipos de definiciones de los derechos humanos y del estudio de las diversas expresiones lexicales a través de las cuales se expresan esta y otras denominaciones que se les aproximan, tales como las de derechos naturales, derechos fundamentales, derechos individuales, derechos subjetivos, derechos públicos subjetivos, libertades públicas, ensaya su propia definición. Para ésta los derechos humanos aparecen como «un conjunto de facultades e instituciones que, en cada momento histórico, concretan las exigencias de la dignidad, la libertad y la igualdad humanas, las cuales deben ser reconocidas positivamente por los ordenamientos jurídicos a nivel nacional e internacional» 40 .

RESPONSABILIDAD POR LA VIOLACIÓN DE DERECHOS FUNDAMENTALES: EFECTO EN TERCEROS

La doctrina alemana ofreció una construcción jurídica refinada al establecer el llamado efecto en terceros (Drittwirkung), o sea la aceptación de que las nor-

37 Ibid., pp. 64-65.

38 Carlos Santiago Nino, Etica y derechos humanos. Buenos Aires: Astrea, 1989, pp. 20 ss.

39 Manuel Atienza, Tras la justicia. Barcelona: Ariel, 1993.

40 Antonio E. Pérez Luño, Derechos humanos, Estado de Derecho y Constitución, $5^{\mathrm{a}}$ ed., Madrid: Tecnos, 1995, p. 48. 
mas fundamentales no sólo influyen en la relación entre el Estado y los ciudadanos, sino igualmente entre ciudadano/ciudadano $y$, en este sentido, tienen un efecto en terceros o un efecto horizontal. «Tanto el problema de construcción como el de colisión resultan de una diferencia fundamental entre la relación Estado/ciudadano y la relación ciudadano/ciudadano. La relación Estado/ciudadano es la relación entre un titular de derecho fundamental y un no titular de derecho fundamental. En cambio, la relación ciudadano/ciudadano es una relación entre titulares de derechos fundamentales ${ }^{41}$.

Pero si hay dificultades en lo que se refiere a los derechos humanos considerados en el órden internacional, en cuanto a la responsabilidad de entidades o personas diferentes al Estado, como más en detalle lo veremos adelante, pues no cabe ya duda sobre los «derechos humanos institucionalizados jurídicamente» 42 para utilizar la definición que da Martin Kriele a los derechos llamados fundamentales o sea, los trasladados al derecho positivo en las respectivas Constituciones.

Felix Ermacora nos enseña que «desde hace mucho ha dejado de tener vigencia el principio según el cual exclusivamente el Estado es obligado por los derechos fundamentales y los derechos humanos» 43 . Incluso en las primeras Declaraciones de derechos ya se conminaba al individuo a la tolerancia con respecto a sus congéneres. No sólo personas naturales, sino también asociaciones de personas, que no son portadoras de poder público, por ejemplo los partidos políticos, están obligados por los derechos fundamentales.

Avanzando más en la teoría del efecto horizontal, Ermacora afirma: «Este efecto obligatorio de las libertades fundamentales y los derechos humanos en la esfera de los individuos e instituciones no dotadas de poder soberano es designado en la teoría alenana como eficacia hacia terceros (Drittwirkung) de los derechos fundamentales; pero es más que eso y significa un efecto para todos (Allwirkung)»44. Un ejemplo típico sería el del derecho a ser tratado por los demás independientemente de los signos raciales. La exclusión de un bus o de un restaurante por estos motivos viola un derecho fundamental y desconoce un derecho humano a la igualdad, que obliga a todos.

\section{EL EFFCTO HORIZONTAL (DRITTWIRKUNG) EN LA CONSTITUCIÓN COLOMBIANA}

La Constitución colombiana de 1991 introdujo cambios significativos en el campo de los derechos humanos y fundamentales, no sólo al ampliar considerablemente los derechos reconocidos constitucionalmente, sino al establecer

\footnotetext{
41 Robert Alexy, Teoria de los derechos fundanentales. Madrid: CEC. 1993, pp. 510-511.

42 Martin Kriele, en el Diccionario de ética, dir. O. Höffe. Barcelona: Crítica, 1994, p. 81.

43 Felix Ermacora. Allgemeine Staatslehre. Berlin: Duncker \& Humblot, p. 747.

44 Ibid., p. 748.
} 
instituciones y procedimientos que permitan hacerlos efectivos. Dentro de estas innovaciones probablemente la de mayor calado ha sido la introducción de la acción de tutela (art. $86 \mathrm{CP}$ ). Con ella los derechos fundamentales dejan de ser puras declamaciones retóricas, como ocurría en las cartas constitucionales anteriores, sin ninguna posibilidad de traducirse en hechos de la realidad para los ciudadanos atropellados por la acción del Estado o de los particulares. Con esta institución se introdujo igualmente el efecto horizontal al extender la acción de tutela a las relaciones entre ciudadanos.

Es así como al estatuír que «toda persona tendrá acción de tutela para reclamar ante los jueces, en todo momento y lugar, mediante un procedimiento preferente y sumario, por sí misma o por quien actúe a su nombre, la protección inmediata de sus derechos constitucionales fundamentales, cuando quiera que éstos resulten vulnerados o amenazados por la acción o la omisión de cualquier autoridad pública» 45 , se dispuso igualmente que «la ley establecerá los casos en los que la acción de tutela proceda contra particulares encargados de la prestación de un servicio público o cuya conducta afecta grave y directamente el interés colectivo, o respecto de quienes el solicitante se halle en estado de subordinación o indefensión» ${ }^{46}$.

Esto ha abierto una enorme ventana para la defensa de los derechos de los más débiles, en las más diversas esferas, como lo muestra la abundantísima doctrina de la Corte Constitucional, que no cabe resumir en este limitado espacio. Vale la pena mencionar si, que ella se ha referido a todos los ámbitos de la vida social, comenzando por las relaciones entre familiares, para proteger los derechos de los hijos o de uno de los cónyuges. De la misma manera en los casos de discriminación por razones de edad, enfermedad, motivos religiosos, y en fin todo aquello que afecte el principio de igualdad en las relaciones entre los ciudadanos.

«En todos estos casos», dice Rodrigo Uprimny, «se trata de relaciones entre particulares en las cuales se ha admitido la eficacia vinculante de los derechos fundamentales, por lo cual es indudable que en el constitucionalismo colombiano los particulares deben responder por la violación de estos derechos. Es más, en Colombia esa eficacia horizontal de los derechos fundamentales está mucho más desarrollada que en otros países. De un lado, porque nuestros jueces constitucionales han asumido, a veces no con una plena conciencia de sus implicaciones, la tesis de la eficacia horizontal inmediata de estos derechos. Y, de otro lado, porque todos los derechos fundamentales tienen eficacia frente a terceros, puesto que la Corte Constitucional declaró inexequibles aquellas partes del Decreto que regula la acción de tutela que restringían la procedencia de esa acción entre particulares a ciertos derechos

45 Constitución Política de Colombia, art. 86.

46 Ibid. 
únicamente [...]. Ahora bien, esta eficacia frente a terceros aparece asociada, según la Corte Constitucional, a la idea misma del Estado social de derecho» 47 .

Como queda claro por lo expuesto anteriormente, no hay duda en cuanto a la «obligación del Estado de extender la fuerza vinculante de los derechos fundamentales» a las relaciones entre ciudadanos, pero esto no disminuye su responsabilidad en el mantenimiento de la vigencia de tales derechos, sino por el contrario, la acrecienta. No se trata de equiparar la responsabilidad del Estado con la de los particulares, ni menos de diluirla o compartirla. Su obligación es, por consiguiente, doble, por la acción o por la omisión de sus funcionarios. No es posible ignorar que el basamento del Estado de derecho, y más áun del Estado social de derecho, está conformado por los derechos fundamentales y constitucionales. En lo que toca a esta última forma de organización política, ellos amplían grandemente el espacio democrático, al perseguir no solo, como el tradicional Estado liberal, la libertad, sino también la igualdad de los asociados.

\section{LA RESPONSABILIDAD EN EI. DERECHO INTERNACIONAL}

Los sujetos del derecho internacional público son los Estados y en lo que se refiere a los derechos humanos no cabe duda en que son ellos los obligados frente a la comunidad internacional. Las cartas y convenciones que prescriben derechos humanos son suscritas por los Estados y a ellos compete establecer las garantías para su preservación y cumplimiento dentro de su órbita territorial.

Lo anterior está sustentado en una concepción jurídica, pero también en los antecedentes históricos y filosóficos de los derechos humanos. La idea misma de derechos humanos surgió en la lucha del individuo por defender sus derechos frente al poder del Estado. Los derechos humanos limitan la omnipotencia del soberano y amplian el campo de acción del ciudadano. Algo más, la idea misma de ciudadano está estrechamente ligada a los derechos humanos, en cuanto derecho civiles y políticos.

Esta fue, hasta hace no mucho, lo que pudiéramos denominar la tesis clásica u ortodoxa con respecto a la responsabilidad por la violación de los derechos humanos: ella sólo podría corresponder al Estado. Sin embargo, en los últimos años, en particular a partir de la segunda posguerra mundial, el derecho internacional ha progresado considerablemente en muchos aspectos y entre ellos en el relativo a los actores o sujetos obligados por su normatividad. La tesis según la cual sólo el Estado es sujeto del derecho internacional se ha ido ampliando, para dar cabida a los pueblos y a los individuos también como sujetos de la comunidad internacional. Los movimientos de liberación nacional nacidos en esa época estuvieron muy ligados a ese reconocimiento, pero

47 Rodrigo Uprimny, en AA. VV., La responsabilidad en derechos humanos. Bogotá: Universidad Nacional de Colombia, 1996, p. 70. 
también el problema de las continuas violaciones de los derechos humanos por los propios Estados con relación a sus súbditos, lo que hace en no pocos casos utópico pensar que esos mismos Estados sean canales idóneos para la tramitación de sus denuncias.

Sin embargo, no son los individuos aún protagonistas o copartícipes, en la escena mundial, sino apenas, como lo observa Cassese, «pueden asomarse a ella con sus protestas. Los Estados buscan, por lo tanto, hacer de todo por obstaculizar el camino de pueblos e individuos en la escena mundial»48. Por el momento eso se ha logrado en alguna medida a través del llamado derecho humanitario, es decir en razón de la guerra y con el propósito de someterla a reglas menos atroces. De su aplicación, y aquí volvemos a nuestro punto central, se derivan sin duda las principales obligaciones para los Estados, pero también están obligados por dicho derecho los grupos rebeldes o insurrectos, en el caso de guerra civil o de alzamientos de tipo político.

Una objeción, ya no de conveniencia práctico-política, sino jurídica, es la falta de sanción o la imposibilidad de imponerla cuando se trata no de un Estado sino de particulares violadores de derechos humanos. A este respecto habría de pensarse que el derecho internacional es un derecho en formación y que un argumento similar se esgrimía en un pasado no lejano con respecto a su obligatoriedad por parte de los mismos Estados. Ya hoy pocos discuten la existencia de un derecho interncional y la concepción monista del derecho internacional ha sido aceptada por muchos Estados, incluído el nuestro, siguiendo el pensamiento de Hans Kelsen ${ }^{49}$. ¿No hay ya atisbos de que algo semejante ocurra con respecto a la participación de sujetos distintos a los Estados en las responsabilidades derivadas de normas de derechos humanos?

Las grandes transformaciones que se operan hay en el mundo han debilitado considerablemente el Estado-nación en la misma medida en que se han creado otros poderes, en algunos casos superiores a los mismos Estados. ¿ Las empresas multinacionales, de las cuales muchos Estados débiles son simples títeres, no violan derechos humanos cuando sacrifican a sus intereses los derechos de los nacionales del respectivo país ? El hecho de que no haya un tribunal internacional que las pueda juzgar por esas violaciones no significa que éstas no existan.

LA CUESTIÓN DE LA SOBERANIÁA

A lo anterior puede oponerse el concepto de soberanía, en opinión de algunos sobre todo dentro de la concepción absoluta que primó a lo largo del Siglo XIX

48 Antonio Cassese, Los derechos humanos en el mundo contemporáneo, pp. 251 ss.

49 Hans Kelsen, Teoría General del Derecho y el Estado, tr. E. García Maynez. México: UNAM, 1949, pp. 345 ss. 
y en buena parte del Siglo $\mathrm{XX}^{50}$. Sin embargo, perteneciendo la totalidad de los países independientes a las organizaciones de la comunidad internacional, comenzando por las Naciones Unidas, y habiendo aprobado y suscrito los compromisos que emanan de las Declaraciones de Derechos, en primer término la Carta Universal, no se ve que sea insuperable la contradicción que pueda presentarse entre la aplicación de los derechos humanos y la soberanía de los países, que en este campo ha cedido, si fuese posible decir, ante el interés superior de preservar y defender la dignidad y los derechos de toda persona humana. Pero esa «cesión» no ha sido impuesta, porque ello si vulneraría el principio de la soberanía nacional de manera inaceptable, sino hecha por los propios Estados al adquirir compromisos que trascienden sus propios territorios, por el carácter mismo de los derechos humanos, en proceso de internacionalización.

La solución a esa antinomia la ve Jürgen Habermas, avanzando sobre Kant, en un «orden jurídico global que congregue a los pueblos y elimine las guerras» ${ }^{51}$, es decir, en el desarrollo de un derecho cosmopolita. En su crítica a la situación actual de desprotección real de los derechos humanos en el orden internacional, pone el acento Habermas en lo que considera el punto más débil: la falta de un ejecutivo «que pudiera proporcionar respeto a la Declaración Universal de los Derechos Humanos, mediante la ingerencia en el poder soberano de los Estados nacionales» 52 . En esta propuesta se concebiría el Consejo de Seguridad como una autoridad ejecutiva con poder sobre fuerzas propias. Al mismo tiempo habría de ampliarse la competencia del Tribunal Internacional de Justicia para poder acusar, dictar sentencias de carácter obligatorio y no simplemente arbitrales; e incluso extender su jurisdicción a conflictos entre personas privadas y entre ciudadanos y sus Gobiernos.

Habermas vuelve aquí a las ideas expuestas por Hans Kelsen en su obra La paz por medio del derecho, que fue uno de los antecedentes doctrinarios de la Organización de Naciones Unidas. Allí el eminente jurista austriaco planteaba un Tribunal Internacional dotado de jurisdicción obligatoria. Pero no como una imposición, sino como resultado de un tratado suscrito por «el mayor número de Estados posible» y con el fin de «renunciar a la guerra y las represalias como medios de resolver los conflictos, a someter todas sus disputas sin excepción a las decisiones del Tribunal, y a cumplir sus decisiones de buena fe» 53 .

También preveía Kelsen un poder ejecutivo centralizado, pero lo consideraba «el más difícil de todos los problemas de la organización mundial» y sólo posible como un último paso. «Un paso que en todo caso no puede darse con

\footnotetext{
50 Ligia Galvis, Comprensión de los derechos humanos. Bogotá: Aurora, 1996, p. 351.

51 Jürgen Habermas, "La idea kantiana de la paz perpetua», Isegoria, 16 (1997), p. 61.

52 Ibid., p. 75.

53 Hans Kelsen, La paz por medio del derecho. Buenos Aires: Losada, 1946, p. 42.
} 
buen éxito antes de que se establezca un Tribunal Internacional y de que éste, mediante sus actividades imparciales, haya conquistado la confianza de los Gobiernos» ${ }^{54}$. Es cierto que la idea de Kelsen no pudo prosperar en su momento, debido principalmente al inicio de la confrontación entre las superpotencias, el clima de guerra fría y la razonable susceptibilidad de los Estados medios y pequeños con relación a su soberanía.

Revividas por Habermas hoy tales propuestas, habría que pensar en un previo proceso de democratización de la Organización de Naciones Unidas, en donde desde su propia conformación, con un núcleo de potencias que se privilegian con el derecho de veto, no puede hablarse sino retóricamente de la «igualdad de los Estados». Pero este es un tema que por su amplitud se sale del objeto de este trabajo y al cual solo se hace referencia en cuanto afecta el problema de los derechos humanos.

\section{DERECHOS HUMANOS Y DERECHO INTERNACIONAL EN COLOMBIA}

El artículo 93 de la Constitución establece que «los tratados y convenios internacionales ratificados por el congreso, que reconocen los derechos humanos y que prohiben su limitación en los estados de excepción prevalecen en el orden interno. Los derechos y deberes consagrados en esta Carta, se interpretarán de conformidad con los tratados internacionales sobre derechos humanos ratificados por Colombia» 55 . No hay duda alguna sobre la primacía que se da al derecho internacional en materia de derechos humanos. Pero el punto relativo a la responsabilidad por su violación sigue siendo motivo de debate.

En una situación como la colombiana, en medio de una guerra crónica en la que intervienen los más diversos actores, donde se violan de manera atróz y permanente los derechos de las personas, empezando por el de la vida, y la mayor parte de tales violaciones se atribuyen a agentes del Estado, cualquier discusión sobre la materia origina inevitables susceptibilidades.

Quienes se oponen a responsabilizar actores distintos al Estado en la infracción de derechos humanos, se fundan en argumentos más de tipo ético-político, que jurídico. La diseminación de la responsabilidad puede servir simplemente para eludir la del Estado, evadir sus obligaciones y tratar de equipararse con grupos o sujetos particulares. En principio habría que decir que sólo el Estado, en situaciones de normalidad, es responsable de las violaciones a los derechos humanos, y los particulares de la infracción a las leyes penales en condición de delincuentes.

Pero esto que es claro en estado de paz, lo resulta menos en una guerra en la que los contrincantes del Estado tienen poder político, dominan territorios,

54 Ibid., p. 50.

55 Constitución Política de Colombia, art. 93. 
ejercen actos que se asemejan a los del mismo Estado, por ejemplo en la aplicación de una justicia propia. Sobre el particular la Comisión Colombiana de Juristas, a través de su Director, Gustavo Gallón Giraldo, sostiene que "grupos no estatales, como la guerrilla, que por su actividad esencial estén expuestos permanentemente a violar derechos fundamentales, no pueden ser considerados en sentido propio como violadores de derechos humanos, en el actual estado de desarrollo del derecho" ${ }^{56}$. A tales grupos les sería aplicable el derecho común, de una parte, y el derecho humanitario, de conformidad con el ius cogens y los convenios internacionales.

La ventaja de esta solución, hasta tanto nuevos progresos en el derecho internacional aclaren las diversas situaciones nuevas que ofrece el mundo actual, es que cierra el camino a los Estados violadores de derechos humanos para extender a tal punto la responsabilidad por este concepto que termine banalizándose el tema y evadiendo las responsabilidades que de manera primordial les corresponden. Lo anterior no impide el paso a futuros desarrollos del derecho internacional, como indudablemente se están dibujando en las discusiones actuales. La tendencia a ampliar los sujetos y actores del derecho internacional, atrás señalada, es uno de estos y no de los menos importantes.

Por encima de todo, y esto podríamos decirlo a manera de conclusión, lo esencial es salir al encuentro de las negaciones expresas o tácitas de los derechos humanos o de su degradación como instrumento político, propugnar por su ampliación y fortalecimiento y la consagración de medios y procedimientos eficaces de amparo y protección. Cabe a los Estados, como miembros de la comunidad de naciones, la principal responsabilidad para realizar esos fines, sin perjuicio de las obligaciones de otros sujetos del derecho internacional, cuya presencia hasta ahora ha sido circunstancial y en todo caso entrabada o vista con recelo por lo Estado, muchas veces a nombre de un falso concepto de «soberanía». Llegar a esos resultados sería viable sin necesidad de imponer modelos absolutos ni de desconocer los legítimos reclamos de respeto por tradiciones culturales, que flagrantemente no los contradigan.

No es posible hablar de democracia y Estado de derecho, menos aún de Estado social de derecho, si no hay la máxima garantía de protección y realización de los derechos humanos y las libertades y derechos fundamentales. Quisiera destacar con unas palabras de Javier Muguerza, que no solo son atinentes al tema, sino que conciernen particularmente a la Filosofía del Derecho y Filosofía Social: «Los iusfilósofos se han limitado hasta ahora a teorizar sobre los derechos humanos (que es, a decir verdad, lo único que pueden hacer y deben seguir haciendo); pero

56 Gustavo Gallón Giraldo, «Responsabilidad del Estado y de grupos no estatales por violación de derechos fundamentales», en AA. VV., La responsabilidad en derechos humanos. Bogotá: Universidad Nacional de Colombia, 1996, p. 28. 
concierne a todo hombre luchar por conseguir que se realicen jurídicamente aquellas exigencias morales de «dignidad, libertad e igualdad» que hacen de cada hombre un hombre, así como por preservar y proteger las convertidas ya en derechos, impidiendo su vaciamiento de sentido y su degeneración en mera retórica tras de haber sido incorporados a los correspondientes textos legales» 57.

A lo anterior habría que agregar que el problema de la responsabilidad por la violación de los derechos humanos, no puede analizarse exclusivamente desde un punto de vista normativo y en definitiva abstracto, sino que ha de tener en cuenta las diversidades culturales de los pueblos, las especificidades de las distintas civilizaciones humanas y aún la diferenciación entre los distintos tipos de organizaciones estatales. El intento de pensadores liberales como Rawls o Barry para llegar a posiciones equilibradas, que permitan avanzar en el respeto a los derechos humanos básicos, que puedan cubrir distintos modelos de sociedades, ha de ser continuado, en el propósito que debe animar a toda Filosofía Jurídica y Política digna de ese nombre, el de conseguir y afianzar la paz entre las naciones, sobre la base de la autodeterminación, la justicia y el acatamiento de los derechos fundamentales. Los principios de democracia y Estado de derecho son por supuesto consubstanciales a esa aspiración. A la luz de esos principios y de un dinámico proceso de ampliación del derecho internacional, podrá concretarse en el futuro de manera más clara la responsabilidad por la violación de los derechos humanos, ya no solo de los propios Estados, sino también de otros sujetos, tal como aquí ha quedado esbozado.

Luis Villar Borda ocupa la cátedra de Introducción a la Ciencia del Derecho en la Universidad Externado de Colombia. Autor de Democracia municipal: autonomía, planificación y desarrollo (Madrid: Instituto de Estudios de Administración Local, 1984) y de Etica, derecho y democracia (Bogotá: Ediciones Jurídicas Gustavo Ibáñez, 1994).

Dirección postal: Universidad Externado de Colombia, Departamento de Gobierno Municipal, Calle 12, № 1-17 Este, A. A. 034141 Bogotá (Colombia).

57 Javier Muguerza, «Carta a Gregorio Peces-Barba», en J. Muguerza y otros autores, El fundamento de los derechos humanos. Madrid: Debate, 1989, p. 17. 